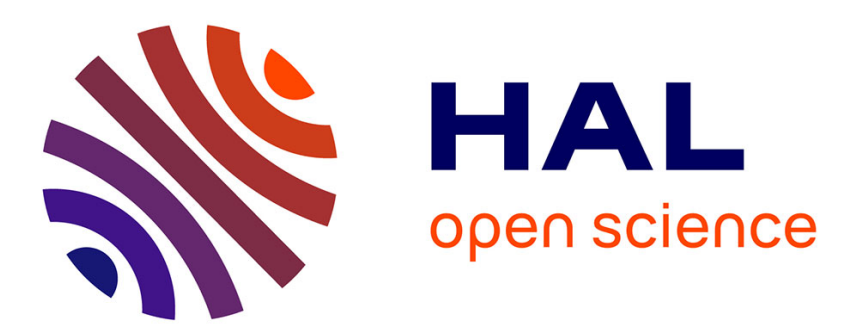

\title{
Fire impact on forest soils evaluated using near-infrared spectroscopy and multivariate calibration
}

\author{
A. Vergnoux, Dupuy N Nom_exemple, M. Guiliano, M. Vennetier, F. \\ Théraulaz, Pierre Doumenq
}

\section{- To cite this version:}

A. Vergnoux, Dupuy N Nom_exemple, M. Guiliano, M. Vennetier, F. Théraulaz, et al.. Fire impact on forest soils evaluated using near-infrared spectroscopy and multivariate calibration. Talanta, 2009, 80, p. 39 - p. 47. hal-00455620

\author{
HAL Id: hal-00455620 \\ https://hal.science/hal-00455620
}

Submitted on 10 Feb 2010

HAL is a multi-disciplinary open access archive for the deposit and dissemination of scientific research documents, whether they are published or not. The documents may come from teaching and research institutions in France or abroad, or from public or private research centers.
L'archive ouverte pluridisciplinaire HAL, est destinée au dépôt et à la diffusion de documents scientifiques de niveau recherche, publiés ou non, émanant des établissements d'enseignement et de recherche français ou étrangers, des laboratoires publics ou privés. 


\title{
Fire impact on forest soils evaluated using near-infrared spectroscopy and multivariate calibration
}

\author{
A. Vergnoux ${ }^{1,2^{\star}}$, N. Dupuy ${ }^{3}, M$. Guiliano $^{1}, M$. Vennetier ${ }^{4}, F$. Théraulaz ${ }^{2}$, P. Doumenq ${ }^{1}$
}

\author{
${ }^{1}$ Université Paul Cézanne Aix-Marseille 3. ISM2, UMR 6263, équipe $A D^{2} E M$, chimie analytique et \\ environnement. Europôle de l'Arbois. Bâtiment Villemin BP 80. 13545 Aix-en-Provence Cedex 4, \\ France. \\ ${ }^{2}$ Université de Provence Aix-Marseille 1. Laboratoire Chimie Provence. UMR 6264. \\ 3 pl. Victor Hugo - Case 29, 13331 Marseille Cedex 3, France. \\ ${ }^{3}$ Université Paul Cézanne Aix-Marseille 3. ISM2, UMR 6263, équipe $A D^{2} E M$, systèmes chimiques \\ complexes. Faculté Saint Jérôme - Case 451, 13396 Marseille Cedex, France. \\ ${ }^{4}$ Cemagref Aix en Provence. Mediterranean Ecosystems and Risks Research Unit. \\ 3275 Route de Cézanne, CS 40061, 13182 Aix en Provence Cedex 5, France. \\ *tel: +33491106380; fax: +33491106377; E-mail: aurore_vergnoux@hotmail.com
}

\begin{abstract}
The assessment of physico-chemical properties in forest soils affected by fires was evaluated using near infrared reflectance (NIR) spectroscopy coupled with chemometric methods. In order to describe the soil properties, measurements were taken of the total organic carbon on solid phase, the total nitrogen content, the organic carbon and the specific absorbences at 254 and $280 \mathrm{~nm}$ of humic substances, organic carbon in humic and fulvic acids, concentrations of $\mathrm{NH}_{4}{ }^{+}, \mathrm{Ca}^{2+}, \mathrm{Mg}^{2+}, \mathrm{K}^{+}$and phosphorus in addition to NIR spectra. Then, a fire recurrence index was defined and calculated according to the different fires extents affecting soils. This calculation includes the occurrence of fires as well as the time elapsed since the last fire. This study shows that NIR spectroscopy could be considered as a tool for soil monitoring, particularly for the quantitative prediction of the total organic carbon, total nitrogen content, organic carbon in humic substances, concentrations of phosphorus, $\mathrm{Mg}^{2+}, \mathrm{Ca}^{2+}$ and $\mathrm{NH}_{4}{ }^{+}$and humic substances $\mathrm{UVSA}_{254}$. Further validation in this field is necessary however, to try and make successful predictions of $\mathrm{K}^{+}$, organic carbon in humic and fulvic acids and the humic substances UVSA 280 . Moreover, NIR coupled with PLS can also be useful to predict the fire recurrence index in order to determine the spatial variability. Also this method can be used to map more or less burned areas and possibly to apply adequate rehabilitation techniques, like soil litter reconstitution with organic enrichments (industrial composts) or reforestation. Finally, the proposed recurrence index can be considered representative of the state of the soils.
\end{abstract}

Keywords: Fire, soil, fire recurrence index, NIR spectroscopy, PCA, PLS

\section{Introduction}

The Mediterranean region is seriously affected by forest fires. Each year more than 50,000 fires burn an estimated average of 600,000 to 800,000 ha. This area represents 1.3 to $1.7 \%$ of the total Mediterranean forests [1]. The studied Mediterranean ecosystem is situated in the Maures Mountains, in the south-east of France, near Sainte Maxime and Saint Tropez. Every year, forest fires cause a lot of damage in this area. Indeed, many physical, chemical, mineralogical and biological soil properties can be affected by forest fires [2]. The extent and duration of the effects of fire depend on the severity of the fire. They are controlled by several environmental factors that affect the combustion process, such as quantity, nature and moisture of live and dead fuel, air temperature and humidity, wind speed and topography of the site [2]. As a remark, it is quite impossible to obtain this data "a posteriori". The status of Mediterranean ecosystems may be balanced with the fire, up to a certain point depending on the frequency of the fires. A high frequency may lead to a significant degradation of the environment and to a reduction of ecological and remediation potentialities. The study of burned soils is necessary to estimate the degradation of soils and to apply adequate rehabilitation techniques like organic enrichment or reforestation. However, it would be very interesting to study the spatial variability of soils affected by fires and to map more or less affected areas taking into account fire frequencies. For such a study in a large area, it is necessary to connect observed changes with an estimation of fire frequencies. Fire-frequency, commonly used for describing or assessing fire regimes, is a rather complex concept which can be based on several descriptors, taking into account time or space, or both time and space [3]. The number of fires at a given point in a given time unit, is the simplest time-based definition for fire-frequency [4]. In such a case, fire interval can be calculated as the average time between two fires, generally many years in forest environments. However fire 
frequency can also be assessed with the distribution of intervals between two fires, or the average age of forest whose age distribution fits a mathematical distribution, for example negative exponential or Weibull [5]. In this work, a fire recurrence index was built, tested and calculated in order to display numerical values representative of the different fire conditions that affect the different soils.

Physico-chemical analyses can also be planned in order to manage the forest, such as organic carbon content, nitrogen content, nutrients and humic substances. However, these techniques are time consuming, expensive and sample destructive. Moreover, a single parameter is insufficient to give an accurate evaluation of the soil alteration. That is why several parameters need to be taken into consideration. So, reliable, inexpensive methods have to be developed for soil analyses.

Near infrared reflectance (NIR) spectroscopy is a fast, simple and non destructive analytical method, with no chemical reagent needed and it is also cost effective. NIR spectroscopy is an alternative method replacing usual physico-chemical analysis. Moreover, the sample preparation is very easy and "in situ" technology application is available. Such advantages lead to an emerging awareness of near infrared spectroscopy as a tool for environmental and biological analyses. NIR spectra contain a wide variety of information due to the absorption of NIR radiation by organic matter, particularly the overtone and combination bands of $\mathrm{C}-\mathrm{H}, \mathrm{N}-\mathrm{H}, \mathrm{S}-\mathrm{H}, \mathrm{O}-\mathrm{H}$ and $\mathrm{O}=\mathrm{C}$ bonds. As a consequence of overlapping bands, it is impossible to directly interpret a spectrum by correlating the intensity or the peak areas with concentrations. That is why NIR spectroscopy should be coupled with statistical methods. Previous works [6-15] have shown the usefulness of NIR spectroscopy for soil analyses in the prediction of some physico-chemical properties, like moisture, organic carbon content, nitrogen content, cation exchange capacity and nutrients $\left(\mathrm{Mg}^{2+}, \mathrm{Ca}^{2+}, \mathrm{K}^{+}, \mathrm{NH}_{4}^{+}\right.$, etc.). In addition, a recent study [16] shows the successful use of burned soils to predict maximum temperature of fires. So, NIR spectroscopy could be a valuable tool for soil characterization and management.

In this work, we have monitored the changes in various physico-chemical characteristics of forest soils affected by different fire recurrences. The measured parameters, in addition to NIR spectra, were total organic carbon, total nitrogen content, aromaticity and organic carbon in humic substances, organic carbon in humic and fulvic acid fractions, $\mathrm{NH}_{4}{ }^{+}, \mathrm{Mg}^{2+}, \mathrm{Ca}^{2+}$ and $\mathrm{K}^{+}$contents.

The aim of this study was to build a numeric model for the prediction of these parameters on the basis of chemometric analyses of NIR spectra of soils samples. A prediction was made of the proposed recurrence index as well as the number of fires and the duration of time since the last fire. The main advantage was to centralize all analyses in one device which can be used "in situ" by low skill level operators. The evaluation of the impact of different fire events on forest soils using near-infrared spectroscopy and multivariate calibration was explored. The aim of the evaluation of fire perturbations was to select the most sustainable management practices.

\section{Experimental \\ Sampling}

The studied area is a Mediterranean ecosystem situated in the Maures Mountains, in the south-east of France (Fig.1). The annual average rainfall is about 800 to $1200 \mathrm{~mm}$. The monthly temperature in the area fluctuates from $12^{\circ} \mathrm{C}$ in December and January to $30^{\circ} \mathrm{C}$ in August; annual average temperature is $20^{\circ} \mathrm{C}$. Regarding vegetation, non disturbed forest soils presents a tree stratum of Quercus ilex L., Quercus suber L., Pinus pinaster Aiton subsp. pinaster. Soils recently affected by fires show a total elimination of the vegetation cover with a reconstitution of the vegetal cover more or less advanced, mainly occupied by herbaceous, fast growing species, Erica arborea L., Cistus monspeliensis L., Quercus suber L. This latter species is also present in these sites due to its high capacity of regeneration after fires.

In our studied area, the fire regime in recent years is correctly known through fire history maps including all medium and larger fires since 1950. These maps were used to select the plots. However, due to the broad spatial distribution of these plots, several fire regimes could be found for the same number of fires, with different fire dates. The chosen sites involve areas unburned for 50 years and areas affected by different fire regimes. So, soil samples were collected at 30 different sampling sites (Fig. 1 and Table 1) in order to represent 6 different fire conditions (NVR: numerous very recent fires, NR: numerous and recent fires, NO: numerous and old fires, FR: few and recent fires, FO: few and old fires, C: control sites, unburned since 1950), with 5 different sites for each condition. These sites are relatively preserved from human impact and have been chosen amongst others for this reason. Moreover, they present similar aspect, exposition, slope, altitude and ecological characteristics. So, in this work the "fire factor" was the sole studied influencing factor. 
Fig.1. Location of the sampling sites in the south-east of France o Numerous very recent fires (Sampling in 2008)
$\triangle$ Numerous recent fires
$\square$ Few recent fires

$\Delta$ Numerous old fires

Few old fires

+ Control

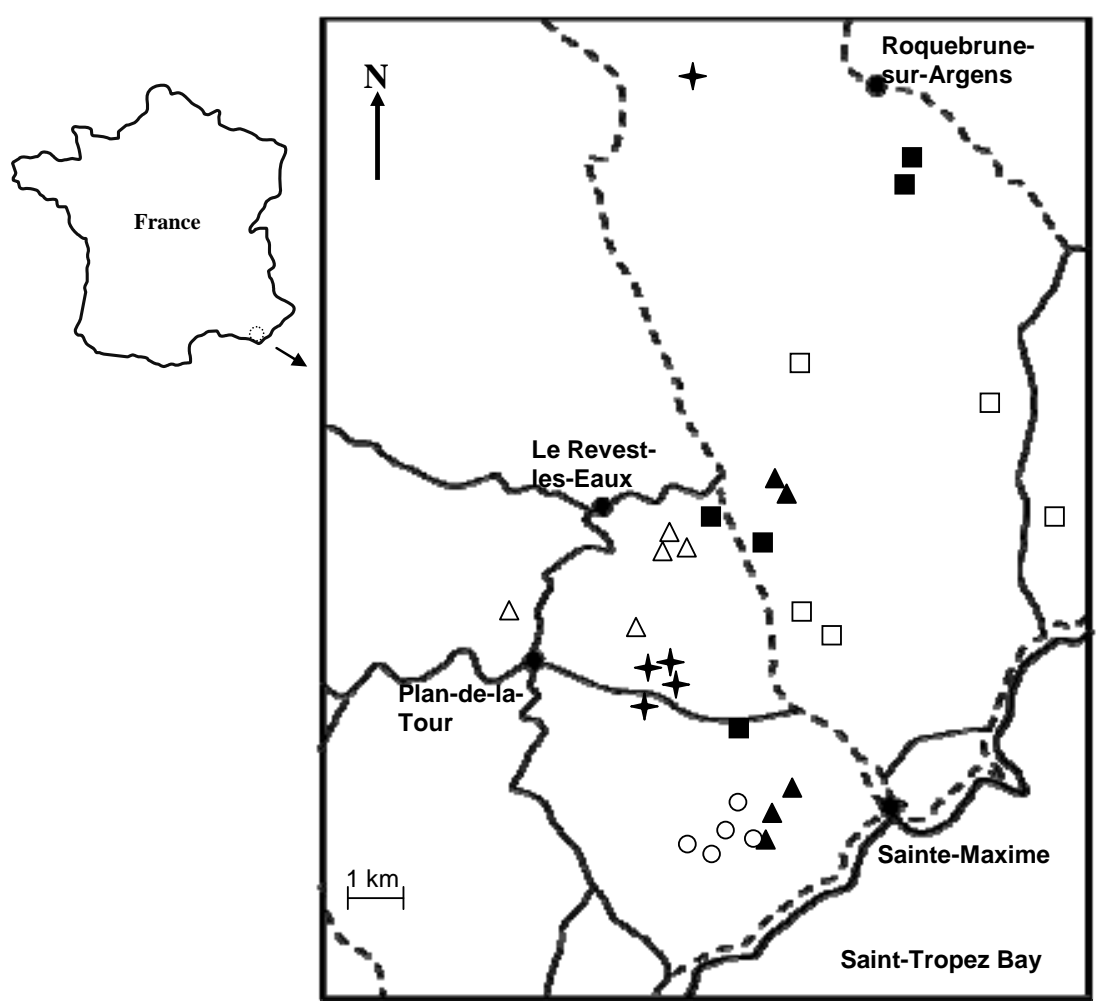

Table 1. Number and dates of the fires affecting the different studied sites

\begin{tabular}{|c|c|c|c|c|}
\hline Condition & & $\begin{array}{l}\text { Number } \\
\text { of fires }\end{array}$ & Dates of forest fire events & $\begin{array}{l}\text { Fire recurrence index } \\
\text { RI }\end{array}$ \\
\hline \multirow{5}{*}{ Control } & \multirow[t]{5}{*}{$\mathrm{C}$} & \multicolumn{2}{|c|}{ Unburned until 1950} & 0.13 \\
\hline & & \multicolumn{2}{|c|}{ Unburned until 1950} & 0.13 \\
\hline & & \multicolumn{2}{|c|}{ Unburned until 1950} & 0.13 \\
\hline & & \multicolumn{2}{|c|}{ Unburned until 1950} & 0.13 \\
\hline & & \multicolumn{2}{|c|}{ Unburned until 1950} & 0.13 \\
\hline \multirow{5}{*}{ Few, old } & \multirow[t]{5}{*}{ FO } & 2 & 1990/1964 & 0.33 \\
\hline & & 2 & 1982/1959 & 0.29 \\
\hline & & 2 & $1990 / 1962$ & 0.33 \\
\hline & & 1 & 1990 & 0.25 \\
\hline & & 1 & 1982 & 0.20 \\
\hline \multirow[t]{5}{*}{ Numerous, old } & \multirow[t]{5}{*}{$\mathrm{NO}$} & 4 & 1990/1985/1978/1964 & 0.60 \\
\hline & & 4 & 1990/1985/1978/1964 & 0.60 \\
\hline & & 4 & $1990 / 1985 / 1978 / 1964$ & 0.60 \\
\hline & & 4 & $1990 / 1982 / 1978 / 1962$ & 0.59 \\
\hline & & 4 & 1990/1982/1978/1962 & 0.59 \\
\hline \multirow[t]{5}{*}{ Few, recent } & \multirow[t]{5}{*}{ FR } & 2 & 2003/1962 & 0.62 \\
\hline & & 2 & 2003/1982 & 0.65 \\
\hline & & 2 & 2003/1982 & 0.65 \\
\hline & & 2 & 2003/1970 & 0.62 \\
\hline & & 2 & 2003/1962 & 0.62 \\
\hline \multirow[t]{5}{*}{ Numerous, recent } & \multirow[t]{5}{*}{ NR } & 4 & 2003/1990/1982/1959 & 0.82 \\
\hline & & 4 & 2003/1990/1982/1959 & 0.82 \\
\hline & & 4 & 2003/1990/1982/1959 & 0.82 \\
\hline & & 3 & 2003/1990/1962 & 0.73 \\
\hline & & 3 & 2003/1990/1970 & 0.74 \\
\hline \multirow{5}{*}{$\begin{array}{l}\text { Numerous, very } \\
\text { recent }\end{array}$} & \multirow[t]{5}{*}{ NVR } & 5 & 2007/1990/1985/1978/1964 & 1.22 \\
\hline & & 5 & 2007/1985/1978/1970/1964 & 1.19 \\
\hline & & 4 & 2007/1985/1970/1964 & 1.12 \\
\hline & & 4 & 2007/1985/1970/1964 & 1.12 \\
\hline & & 4 & 2007/1985/1978/1964 & 1.13 \\
\hline
\end{tabular}


First, the soils NR, NO, FR, FO and C were sampled in May 2006 for two layers (A: $0-5 \mathrm{~cm}$ and B: -5 $-15 \mathrm{~cm}$ ). Then, according to the first results, a second sampling was done in May 2008, only for the A layers of NVR soils.

To take soil heterogeneity into consideration as much as possible, sampling was carried out on five positions at each site, resulting in 5 replicates per layer and per site. Then, equal volumes of the five replicates were mixed, homogenized and sieved $(2 \mathrm{~mm})$, to obtain one composite sample per site and per layer. The soil samples were then stored in glass bottles at $-18^{\circ} \mathrm{C}$ before analysis. Each sample was divided into two equal parts: one for physico-chemical analyses, and another for near infrared spectroscopy.

\section{Fire Recurrence Index}

To take into account the resilient dynamics of studied parameters, fitting fire-frequency to these parameters required a fire-frequency index (FRI). This had to be designed to include not only the number of fires, but also their dates and the time interval between fires.

So, a fire recurrence index was defined and calculated for all soils in order to assess the number and the date of fires according to equation (1).

$$
R I=\sqrt{\sum_{i=1}^{n} \frac{i}{\left(S-F_{i}\right)}}
$$

where $\mathrm{S}$ is the sampling year, $\mathrm{n}$ the total number of fires, $\mathrm{i}$ the number of the fire from more recent to older fires ( 1 for the most recent, 2 for the second most recent, etc.) Fi the years of the fire $i$. This equation takes into account the date of the fires by the difference between the year of sampling and the year of fires in the denominator. The more recent the fire, the greater the result of the division. Then, the number of fires appears by the number of divisions, with a multiplying factor to accentuate the fact that many fires have a bigger impact on the soils. Finally, a square root of the sum is applied to reduce the variability of the values displayed for very recent fires.

\section{Physico-Chemical Analyses}

Humic substances (HS), humic acids (HA) and fulvic acids (FA) amounts were obtained after alkali extraction $(\mathrm{pH}=13.0$ for $20 \mathrm{~h})$ and precipitation of humic-like fraction $(\mathrm{pH}=1.0)$ by addition of 6 mol.L ${ }^{-1} \mathrm{HCl}$. Then, FA were cleaned-up with a column packed with XAD-8 resin. This method was adapted from [17].

HS, HA and FA in solution were analyzed using a high temperature combustion carbon analyzer (Shimadzu TOC analyzer 5050A, Shimadzu) in order to determine organic carbon concentrations (OC). Before analysis, all fractions were acidified to $\mathrm{pH} 2.0$ with $\mathrm{HCl}$ to eliminate residual inorganic carbon and then $\mathrm{N}_{2}$ bubbled during 10 minutes to remove dissolved $\mathrm{CO}_{2}$.

Total organic carbon contents (TOC) of soils were quantified with the same analyzer coupled with a solid module. Organic carbon concentrations were expressed in g. $\mathrm{kg}^{-1}$ of dried soil.

UV absorbance spectra were recorded at room temperature for HS. Acquisition was performed using 1 cm quartz cell with an UV-Vis spectrometer (UV-light, Secomam, France). Data was processed using LabPowerJ ${ }^{\mathrm{TM}}$ software package (Secomam, France). Spectra were recorded with a resolution of $1 \mathrm{~nm}$ between 200 and $400 \mathrm{~nm}$. UV specific absorbances (UVSA) were calculated at 254 and $280 \mathrm{~nm}$ according to the equation $(2)[18,19]$.

$$
\text { UVSA }_{254}=\frac{\text { Absorbance } 254 \mathrm{~nm}}{\text { OC }(\mathrm{mg} / \mathrm{l})} \times 100
$$

The UVSA 254 and UVSA 280 represent the humic substance aromaticity.

The total nitrogen content (g. $\mathrm{kg}^{-1}$ ) was obtained with a combustion method NF ISO 13878. Ammonium plus ammonia nitrogen were extracted from soils in a $\mathrm{KCl}$ solution [20, 21]. Ammonium content in the extract was determined by continuous flow colorimetry [22, 23], and expressed in mg.kg . $^{-1}$

Phosphorus contents, expressed in g.100g $\mathrm{g}^{-1}$, were determined according to the Joret Hebert method $[24,25]$ which is a standard method (AFNOR NF X 31-161).

Exchangeable potassium, magnesium and calcium contents $\left(\mathrm{g} \cdot \mathrm{kg}^{-1}\right)$ were obtained by the standard method AFNOR NF X 31-108 which uses exchangeable cation extraction by ammonium acetate [2628]. 
For the physico-chemical parameters, the standard error of every method (SEM) was calculated according to equation (3).

$$
\mathrm{SEM}=\sqrt{\frac{\sum_{\mathrm{i}=1}^{\mathrm{N}_{1}}\left(\mathrm{X}_{\mathrm{i}}-\overline{\mathrm{X}_{1}}\right)^{2}+\sum_{\mathrm{j}=1}^{\mathrm{N}_{2}}\left(\mathrm{X}_{\mathrm{j}}-\overline{\mathrm{X}}_{2}\right)^{2}+\sum_{\mathrm{k}=1}^{\mathrm{N}_{3}}\left(\mathrm{X}_{\mathrm{k}}-\overline{\mathrm{X}_{3}}\right)^{2}+\ldots}{\mathrm{N}_{1}+\mathrm{N}_{2}+\mathrm{N}_{3}+\ldots+\mathrm{N}_{\mathrm{t}}}}
$$

where $i, j, k, \ldots$ are different samples analyzed with the same method; $N_{1}, N_{2}, N_{3}, \ldots$ are the number of replicates for each sample; $X$ are the measured values; $\bar{X}$ is the mean of the different $X ; N_{t}$ is the total number of samples.

We assumed that the random error sources are the same for all measurements, because the different samples have similar composition and have been analyzed with the same analytical method.

For each analytical method, the relative error of the method (REM) was also calculated according to equation (4).

$$
\mathrm{REM}=\frac{\mathrm{SEM}}{\overline{\mathrm{Y}}} \times 100
$$

where $\overline{\mathrm{Y}}$ is the mean of the values measured by the corresponding analytical method.

\section{Near Infrared Spectroscopy}

Soils were dried and ground before spectroscopic analyses. Aliquots of around $50 \mathrm{~g}$ of soil samples were placed in a specific round glass sampling cup.

Fourier Transformation near Infrared (FT-NIR) spectra were recorded in reflectance with an integration sphere using a Nicolet Antaris spectrometer interfaced to a computer. Spectra were computed at $8 \mathrm{~cm}^{-1}$ resolution from 4500 to $10000 \mathrm{~cm}^{-1}$ using Thermo Nicolet 2.1 software. Coaddition of 64 scans symmetrical interferograms was performed for each spectrum, resulting in 1557absorbance point's spectra.

Three spectra per sample were collected at ambient temperature (total of 165 spectra). For each sample, the subset of 3 spectra was then reduced to 1 by working out an average. Lastly, for each sample measurement, the background correction was obtained using a clean empty glass cup before each sample scan. These latter spectra were then used for PCA and PLS (55 spectra). Spectral pretreatment and multivariate calibration were performed with Unscrambler (version 9.0 from CAMO, Norway).

\section{Principal Component Analysis}

Principal component analysis (PCA) is a method for extraction of the systematic variations in one data set [29]. This method can be used for visualizing information in large data sets as well as for interpretation [30]. In this work, PCA was employed to verify the feasibility of classifying soils according to the fire event that affects them. This tool can show if physico-chemical and spectral results are differentiated by the different kinds of fire events. So, two different PCA were achieved with the A layer of all the studied sites: one with the spectral data and another one with physicochemical parameters. The second one also allowed us to understand the impact of fires on the physicochemical properties of the soils. For the PCA with spectral data, multiplicative scatter correction (MSC) of the original spectra was used [31].

\section{Partial Least Square Regression}

Partial Least Square (PLS) regression is a powerful multicomponent analysis. PLS [32-34] allows a sophisticated statistical approach using the full spectral region rather than unique and isolated analytical absorption bands.

In our case, we are only looking for physico-chemical modifications, i.e. total organic carbon, total nitrogen content, ammoniacal nitrogen, humic substances, humic and fulvic acids, using the same data processing.

The evaluation of the calibration performance was estimated by computing both the standard error of calibration (SEC) after comparing the real modification with the computed one for each component and the standard error of prediction (SEP) for the estimation of the prediction performance during the step of validation of the calibration equation. Additionally, we used the relative error of prediction (REP) that shows the predictive ability of the model. 
With regards to calibration and prediction of the models; after rather inconclusive tests with different parts of spectra, the whole spectra were chosen to be used for calculation.

Firstly, the physico-chemical parameters of the soils were modeled by PLS1 with all samples both A and B layers. PLS1 is a version of the PLS method in which only one Y-variable is modeled. Models were constructed using full cross validation to define the factor number (FN). A set of 44 samples was then used for the calibration to establish the model. The validation set composed of 11 samples. One soil of each kind of fire event and each layer was randomly selected to constitute this validation set in order to evaluate the ability of the multivariate calibration method for prediction. The PLS1 regression was achieved with different spectroscopic pretreatments of the spectra: no data processing, MSC, standard normal variate (SNV), normalization, first derivative and smoothing [35]. In each case, we chose the pretreatment leading to the best correlation between spectra and physico-chemical data.

Then, in the same way as for physico-chemical data, three other variables were modeled by PLS1 with the multiplicative scatter corrected spectra only for the A layer. These variables are: number of fires (NF), time elapsed since the last fire (TE) and the fire recurrence index (FRI). MSC was chosen because it displayed the best correlation between spectra and these three variables. The calibration and validation sets were constituted of 24 and 6 samples respectively.

\section{Results and discussion \\ Fire Recurrence Index}

To take into account the resilient dynamics of studied parameters, fitting fire-frequency to these parameters required a fire-frequency index. This had to be designed to measure not only the number of fires but also their dates, the time in between and the last fire, and the time interval between fires. An area-based index was not required as plots were considered as points in the landscape.

So, on the basis of the sampling year S, the total number of fires (n) and the date of the fires (Fi), the fire recurrence index (FRI) was designed (i) to increase with the number of fires and (ii) to decrease in a negative exponential way with the time since the last fire. It was designed to fit in with what was observed with the dynamics of most of the parameters and, more generally (iii) to give more importance to recent fires than to old fires. FRI was computed with the equation (1) (see experimental).

Fig. 2 shows the graphical results of RI calculated values by the simulation of different fire conditions with a sampling date in 2008. The abscissa axis represents the date of the last fire, which is the only variable in the FRI equation. For calculation with several fires, the other dates of fire are held fixed (captions in Fig.2). FRI values were calculated in this way from 1 to 4 fires, moving the date of the last fire and changing intervals between fires.

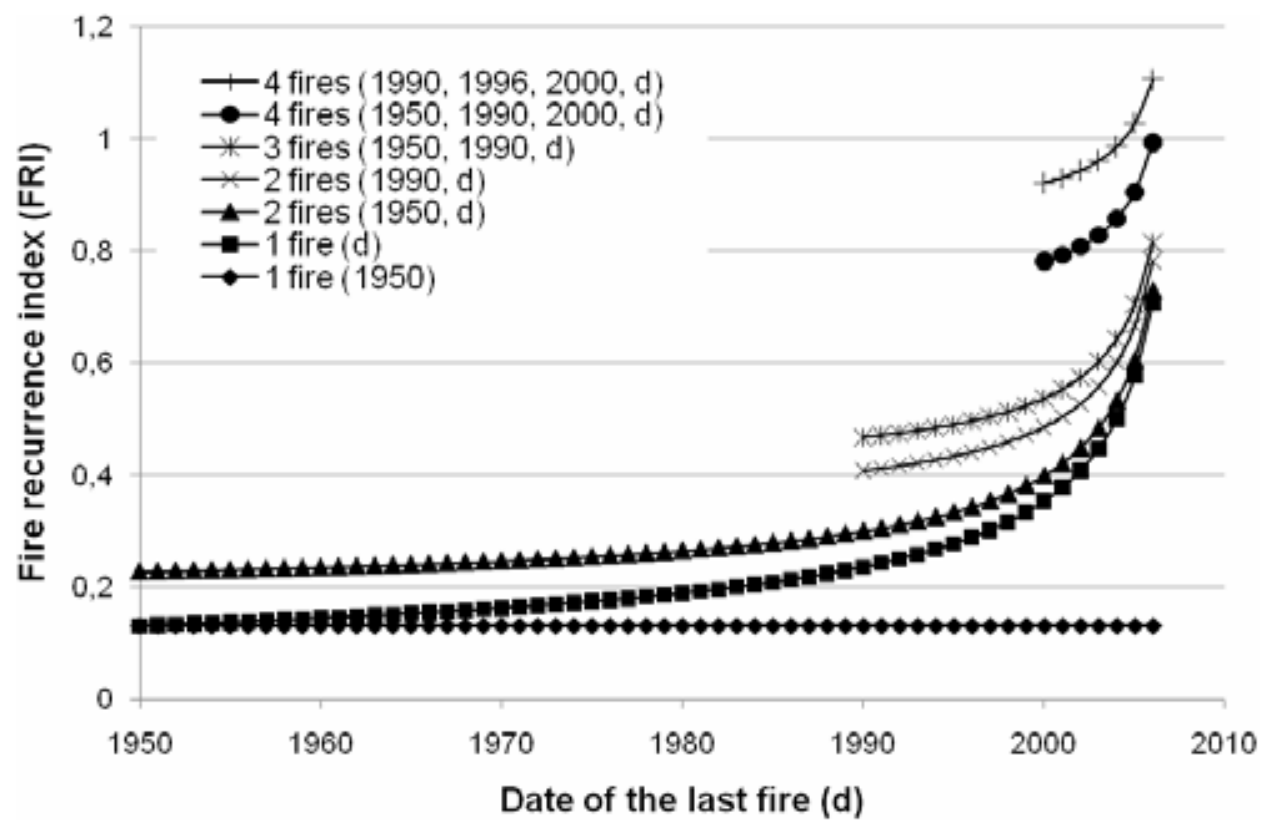

Fig.2. FRI calculated values by the simulation of different fire conditions. Sampling date is 2008. 
The FRI values show that a hierarchy between the different fire recurrences exists according to both fire number and dates of the fires. Moreover, comparing results for the 2 conditions with 4 fires, the FRI values are greater when the fires are grouped around the same time than when they are becoming less frequent. So, the index takes into account the notion of a greater impact caused by frequent fires. Table 1 shows the calculated FRI for all sites. The controls, unburned since 1950, present a FRI of 0.13 . The highest value obviously corresponds to the more impacted site and reaches 1.22 . It represents 5 fires about every 15 years since 1964, the last one being in 2007. The other values consequently range from 0.13 to 1.22 , reaching about $0.25,0.60,0.65$ and 0.78 for FO, NO, FR and NR respectively. So, the FRI values of the studied sites are arranged according to a "theoretical fire impact”.

\section{Spectral Data}

Fig. 3 shows representative spectra of the different soils affected by the different fire conditions. All spectra are very close and look like those of a previous study of Mediterranean soils [14]. According to previous works $[7,11,13,14,36]$, all NIR spectra showed 3 large absorption bands due to harmonic and/or combination vibrations at: (i) $4530 \mathrm{~cm}^{-1}$, combination of the $\mathrm{CH}, \mathrm{NH}, \mathrm{OH}$ stretching vibration with other; (ii) $5200 \mathrm{~cm}^{-1}$, first overtone of $\mathrm{CH}$ stretching vibration (methyl, methylene and ethylene groups); (iii) $7065 \mathrm{~cm}^{-1}$, combination of the $\mathrm{CH}$ stretching vibration.

We notice that soil spectra are arranged in order along the absorbance axis, from old to recent fires. The latter condition leads globally to a significant increase of the baseline of absorbance spectra [16], particularly in the spectral domain from 5500 to $10000 \mathrm{~cm}^{-1}$. Consequently, the spectra of soils recently burned are at the top of Fig. 3 whereas the spectra of control and formerly burned soils are at the bottom.

The interpretation of individual spectra nevertheless remains difficult. So, all additional information needs to be and will be "extracted" and highlighted by statistical treatments as Principal Component Analysis and Partial Least Square regression as described in the following section.

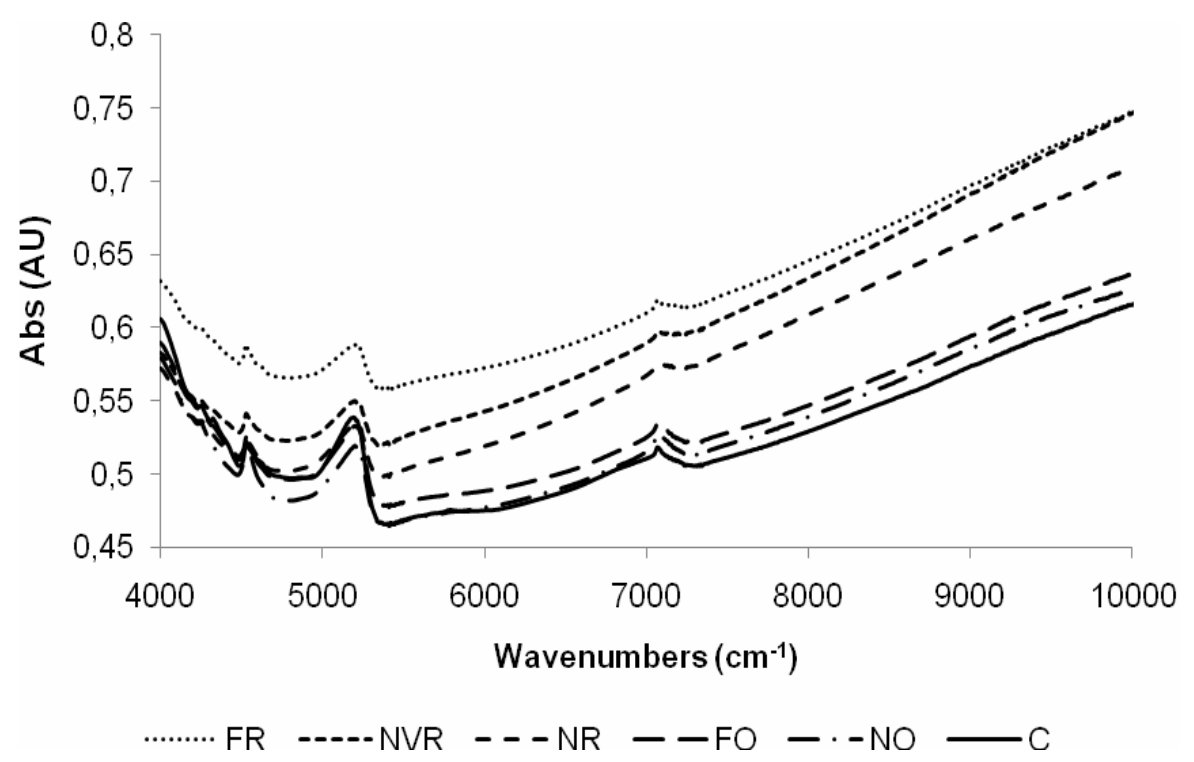

Fig. 3. Representative spectra from the soils affected by different recurrences of fires. Each presented spectra is the average of 3 raw spectra.

NVR: numerous very recent fires NR: numerous recent fires FR: few recent fires

NO: numerous old fires $\quad$ FO: few old fires C: control

(A) Combination of the $\mathrm{CH}, \mathrm{NH}, \mathrm{OH}$ stretching vibration with other vibrational modes. (B) First overtone of $\mathrm{CH}$ stretching vibration (methyl, methylene and ethylene groups). (C) Combination of the $\mathrm{CH}$ stretching vibration.

\section{Principal Component Analysis of the Spectral Data}

Fig.4 shows the principal component analysis for NIR spectra after MSC correction of control and soils affected by the different fire conditions for the A layer. About $99 \%$ of the total spectral variance was explained after computing the first principal component on corrected spectra. 
The samples are represented by bars positioned from left to right, according to the fire recurrence. The bargraph shows 2 differentiated zones. The first one gathers spectra of soils affected by recent fires, showing negative scores. The second one corresponds to spectra from controls and soils affected by old fires, showing positive scores except for 2 samples.

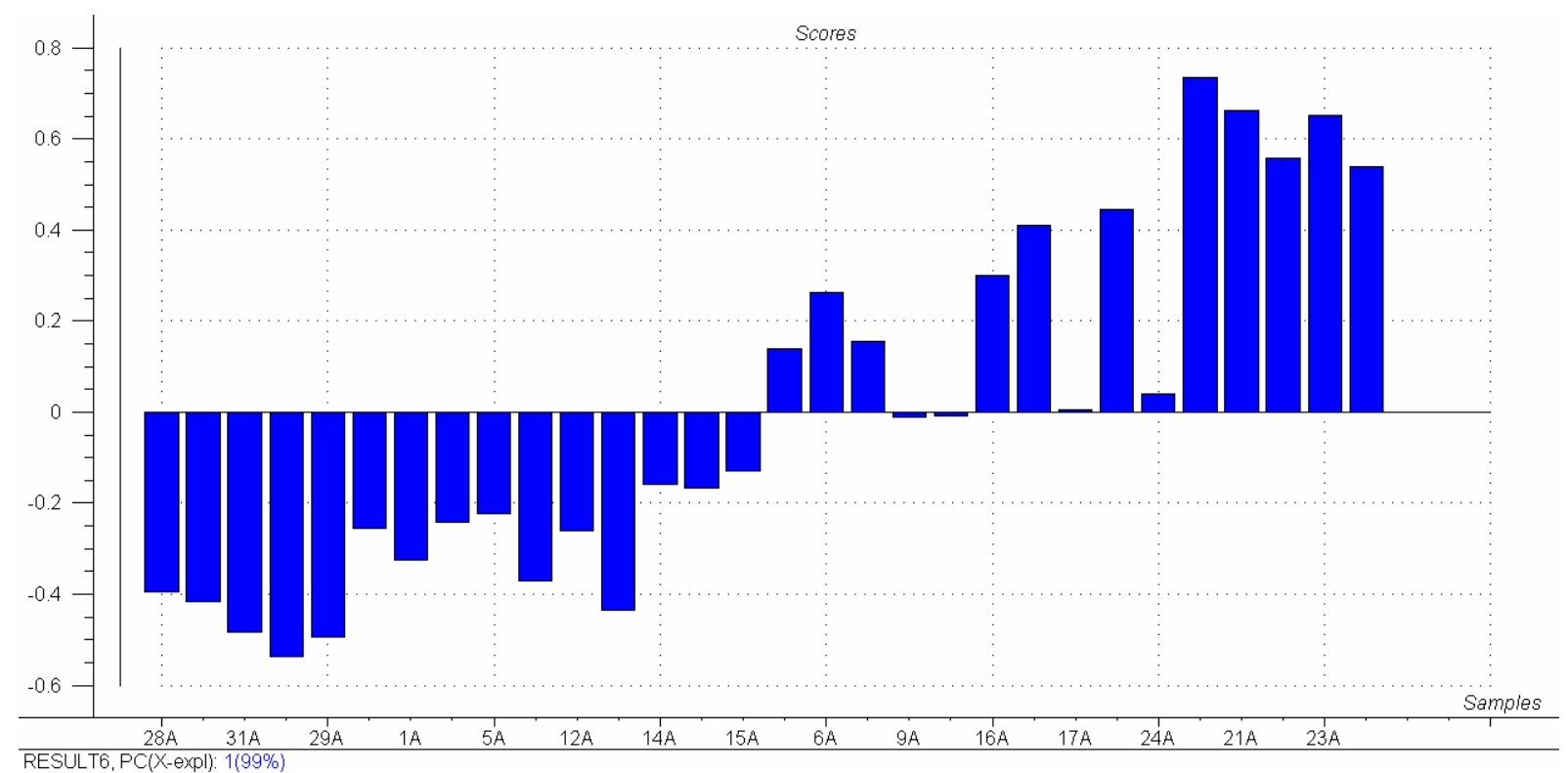

Fig. 4. Principal component analysis for multiplicative scatter corrected spectra of the layer A of soils.

NVR: Numerous very recent fires NO: Numerous old fires

NR: Numerous recent fires FO: Few old fires

\section{FR: Few recent fires} C: Control

The examination of the first loading plot (Fig. 5) showed a similarity with sample spectra, they have the same 3 absorption bands at 4530, 5200 and $7065 \mathrm{~cm}^{-1}$. However, these bands present higher intensity in the first loading plot. Spectra with positive scores (Fig. 4, control and soils affected by old fires) are correlated to the positive part of the first loading plot, i.e. A and B bands, which are relative to the organic matter content. Spectra with negative scores (Fig. 4, soils affected by recent fires) are correlated to the negative part of the first loading plot, i.e. C band and the baseline shift, which could represent inorganic matter. So, recent fires and old fires can respectively be allocated to spectra with a large baseline deviation and spectra with intense A and B bands due to high organic matter amounts (Fig.3).

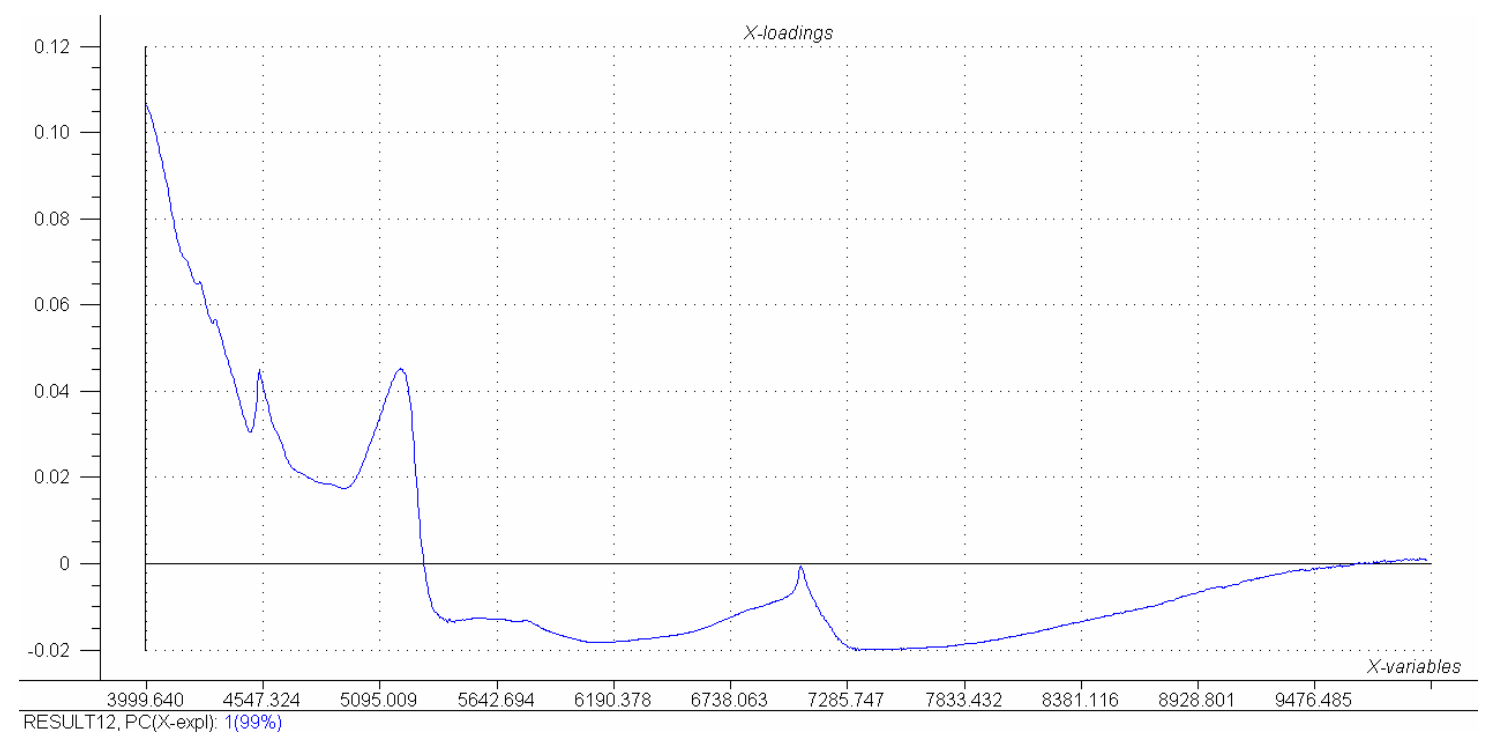

Fig. 5. First loading plot (99\% of the variance). 
These baseline drifts were previously shown by Zornoza et al. [14], for soils with different land-uses. We also found such drifts in industrial compost NIR spectra in a previous work [37]. Generally, baseline drifts in IR are due to light scattering because of samples granulometry (as a result of soil grinding) and/or sample composition (organic and/or inorganic).

It clearly appears that it is possible to assess the spatial heterogeneity of a burned area in this way. So, PCA can be a useful, rapid and inexpensive method for monitoring forest soils and planning adapted remediation strategies.

Soils affected by old fires are differentiated from control sites (Fig.4). Sixteen years after the last fire, the burned soils do not return to the control state. Moreover, Fig. 4 shows that the variability between old fires is greater than the variability between recent fires. Recent fires clearly homogenize the soils. After that, the reconstruction is more or less efficient, conducting to contrasted results as shown by NO and FO fires. It suggests variability in "remediation rates" at the site level. Nevertheless, after sufficient period of time (e.g. controls), the samples seem more homogeneous. Finally, it is quite difficult to differentiate numerous fires from few fires or recent or old fires. The preponderant factor that differentiates soils appears to be the time elapsed since the last fire. The difficulty to differentiate few from numerous fires can be explained by the intensity of the fires that affected the soils [16, 38]. The intensity of fires consists of the maximum temperature reached, and the duration of fire. These latter parameters cannot be taken in account here, but remain important for the evaluation of the fire impact. Few, intense fires could lead to a greater impact than less intense, numerous fires.

\section{Principal Component Analysis of the Physico-Chemical Parameters}

Table 2 highlighted for each considered parameter, the mean, the standard deviation and the range for all studied soils and depths. The displayed variability and range are important due to the different recurrence conditions and depths computed.

Table 2. Variability of soil physico-chemical parameters.

\begin{tabular}{|c|c|c|c|c|}
\hline Parameter & $n^{g}$ & Mean & Minimum & Maximum \\
\hline TOC $^{a}$ & 55 & 30.6 & 14.2 & 81,0 \\
\hline Total $\mathrm{N}^{\mathrm{b}}$ & 50 & 1.57 & 0.63 & 4.31 \\
\hline Phos $^{c}$ & 50 & 0.10 & 0.06 & 0.15 \\
\hline $\mathrm{Mg}^{+\mathrm{d}}$ & 50 & 0.23 & 0.10 & 0.49 \\
\hline $\mathrm{Ca}^{2+d}$ & 50 & 1.51 & 0.59 & 3.59 \\
\hline $\mathrm{NH}_{4}{ }^{+d}$ & 50 & 7.12 & 2.29 & 33.50 \\
\hline $\mathrm{OCHS}$ & 55 & 9.50 & 3.56 & 19.90 \\
\hline $\mathrm{OCH} \mathrm{A}^{\mathrm{e}}$ & 55 & 2.30 & 0.53 & 6.10 \\
\hline$O C F A^{e}$ & 55 & 2.50 & 0.92 & 5.40 \\
\hline $\mathrm{UVSA}_{254} \mathrm{HS}^{\dagger}$ & 55 & 3.17 & 2.06 & 4.56 \\
\hline UVSA $_{280} \mathrm{HS}^{\dagger}$ & 55 & 2.73 & 1.68 & 3.93 \\
\hline
\end{tabular}

a: total organic carbon $\left(\mathrm{g} \cdot \mathrm{kg}^{-1}\right) ;^{\mathrm{b}}:$ total nitrogen $\left(\mathrm{g} \cdot \mathrm{kg}^{-1}\right) ;^{\mathrm{c}}:$ phosphorus $\left(\mathrm{g} \cdot 100 \mathrm{~g}^{-1}\right)$;

d: contents $\left(\mathrm{g} \cdot \mathrm{kg}^{-1}\right)$; ${ }^{\text {e: }}$ organic carbon in humic substances, humic acids and fulvic acids $\left(\mathrm{mg}^{-1} \mathrm{~g}^{-1}\right)$;

${ }^{\mathrm{f}}$ : specific absorbance at $254 \mathrm{~nm}$ and $280 \mathrm{~nm}$ of humic substances; ${ }^{9}$ : sample number.

Fig. 6 shows the positions of the samples (and variables) along the two PC. Contrary to the previous spectral PCA, it is impossible to distinguish the different kinds of fire recurrences with only one axis. However, we note the separation of the A layer of recently, and very recently burned soils from formerly burned soils and from controls. This shows three different clusters respectively, A, B and C. They are distributed from the bottom right to the top left of the graph.

The position of the variables in the set of axis shows their relative contribution to the PC's construction. $61 \%$ of the total variance was explained by two components. The first PC, explaining $40 \%$ of the compositional data, is positively correlated to total nitrogen, organic carbon of humic substances and humic acids and with $\mathrm{NH}_{4}{ }^{+}$. In the same way, the second PC, explaining $21 \%$ of the compositional data, is positively correlated to the UVSA 254 and $\mathrm{UVSA}_{280}$.

The proximity of the A cluster with the variable UVSA $_{254}$ and $\mathrm{UVSA}_{280}$ indicates high specific absorbance values at 254 and $280 \mathrm{~nm}$ for soils affected by NVR, NR and FR fires included in this cluster. Moreover, the position and separation of the three clusters can be explained by the UVSA $\mathrm{A}_{254}$ 
and UVSA $_{280}$ representing the HS aromaticity. The soils, both very recently and recently burned show a greater HS aromaticity than the formerly burned soils. These present in their turn, a greater HS aromaticity than the controls. This trend was described in previous works, showing that in burned soils, new aromatic structures are issued from the alteration of carbohydrates [39-42], lipids and peptides [43, 44].

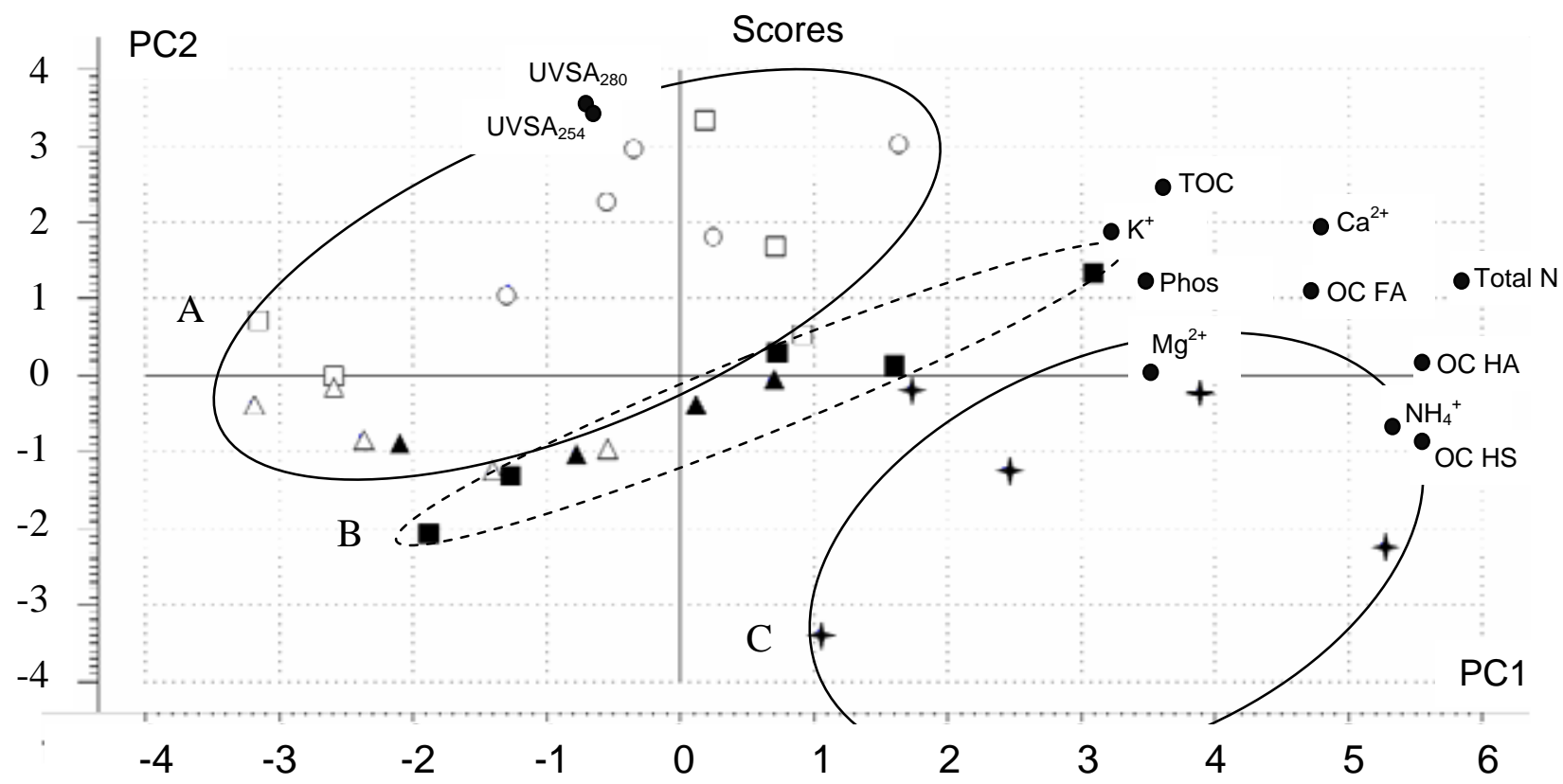

X-expl 40\%, 21\%

Fig. 6. Two dimensional plot of the layer A of soils using physico-chemical parameters.

o Numerous very recent fires

$\Delta$ Numerous old fires

$\triangle$ Numerous recent fires

Few old fires

$\square$ Few recent fires

UVSA $_{254}$ and UVSA 280 : HS specific absorbance at 245 and $280 \mathrm{~nm}$ respectively;

Phos: phosphorus; Total N: total nitrogen; TOC: total organic carbon; OC HS, OC HA and OC FA: organic carbon in humic substances, humic acids and fulvic acids respectively;

(A) cluster with soils affected by very recent and recent fires; (B) cluster with soils affected by old fires;

(C) cluster with control soils.

PC1 and PC2 respectively for principal component 1 and 2.

The soils affected by NVR can be differentiated from those affected by NR by the organic carbon content, nitrogen and some nutrients. The soils affected by NVR present greater organic carbon contents, nitrogen and nutrients. After a moderate wildfire, an increase of carbon in soil is usually observed, suggesting a substantial incorporation of forest necromass [45]. Increases in soil organic matter content are also reported, due to an increased deposition of dry leaves and more or less charred plant materials in fires that affect the tree canopy [46].

Fig. 6 shows lower TOC contents for NR soils. This is probably due to an alteration of changes in soil physico-chemical properties $[47,48]$. Furthermore, the well known soil erodibility accentuates the loss of the soil organic matter by leaching of topsoil layers [49-51].

The FR soils are scattered, probably because of the intensity of fires once again.

For NO and FO conditions, the soils are not discriminated according to the number of fires, but are grouped in the cluster B (Fig. 6). The observed differences could again be attributed to the intensity of fires and above all, to their different reconstitution level since the last fire.

Moreover, the control soils present the greater concentrations of organic carbon contents, nitrogen and nutrients. According to previous works, the fires have a quantitative impact on the nutrients and a quantitative and qualitative impact on the organic matter [2].

\section{Predictions by NIRS}

Physico-Chemical Parameter Predictions

In this part, we try to predict physico-chemical parameters with multivariate calibration models, using the NIR spectra, by partial least squares regression (PLS). The calibration set comprises of 44 samples. 
The evaluation of the results was done with standard error of calibration (SEC), $\mathrm{R}^{2}$ of calibration, standard error of prediction (SEP), $\mathrm{R}^{2}$ of prediction, relative error of prediction (REP) and a number of factors from the PLS model (FN). The more FN are used, the greater is the noise in the model. Table 3 shows the best results obtained for physico-chemical parameters predictions with various spectral treatments.

The majority of the physico-chemical parameters are better calibrated and predicted with SNV pretreatments. Results show that all physico-chemical parameters are very well correlated to NIR spectra, with $\mathrm{R}^{2}$ for calibration mainly over 0.90 . The exceptions are $\mathrm{NH}_{4}{ }^{+}, \mathrm{HS} \mathrm{UVSA}_{254}$ and $\mathrm{UVSA}_{280}$ and the OC of FA which exhibit slightly lower $\mathrm{R}^{2}$ for calibration, $0.84,0.89,0.77$ and 0.62 respectively. Nevertheless, for all physico-chemical parameters, the observed SEC values are relatively low.

PLS models were validated by an independent prediction set of 11 samples. According to a previous work [52], $0.66<\mathrm{R}^{2}$ prediction $<0.8$ indicates a rough quantitative prediction, $0.81<\mathrm{R}^{2}$ prediction $<0.9$ a good prediction and $\mathrm{R}^{2}$ prediction $>0.9$ an excellent prediction. In our study, all $\mathrm{R}^{2}$ for the prediction are greater than 0.9, except for HS UVSA $254 \mathrm{UVSA}_{280}$. These results allow us to expect excellent predictions. It is possible to verify this with the observation of REP values. The predictions seem very good for 5 parameters (TOC, total nitrogen, phosphorus, $\mathrm{Mg}^{+}$and OC in HS), with corresponding REP about $10 \%$. The prediction of the OC in HS is particularly interesting because the REP is very close to REM (table 3) and the usual analytical method is very time-consuming. For other parameters: $\mathrm{Ca}^{2+}$, $\mathrm{NH}_{4}{ }^{+}$and the HS UVSA 254 , the predictions are not as good, with REP ranging from 15 to $20 \%$. Concerning OC in HA and FA and the HS $\mathrm{UVSA}_{280}$, the corresponding REP are too significant to consider an acceptable prediction. Nevertheless, the differences between REP and REM, of about $10 \%$, are not so great for the OC in HA and FA, as the usual analytical methods present REM to be quite important. Table 3 does not show results for $\mathrm{K}^{+}$, because, as for previous works [13, 53], no correlation was found between results and NIR spectra. One explanation could be the non-direct relationship between $\mathrm{K}^{+}$and NIR absorption bands.

Finally, according to previous works [6, 7, 10,11, 13-15, 36, 54-57], these results show the ability of NIR to predict some physico-chemical parameters of soils.

As a partial conclusion, this study shows that PLS regression models using NIR spectra are a valuable tool to assess wildfires effect on impacted soils.

\section{Other Parameter Predictions}

In this part, the prediction of three other variables was realized by PLS1 regression of the multiplicative scatter corrected NIR spectra for A layer of all soils. These variables are: number of fires (NF), time elapsed since the last fire (TE) and the recurrence index (FRI) described above. The calibration set comprises of 24 samples. The number of samples is less than for the physico-chemical parameters because these parameters are only evaluated for A layer. As a remark, A layer was chosen because it is obviously the most impacted by wildfires.

Table 4 shows the best results obtained for calibrations and predictions. TE and RI are very well correlated to corrected NIR spectra. Their $\mathrm{R}^{2}$ of calibration values are over 0.90 and they present low SEC. As regards NF, results are not as good, with $\mathrm{R}^{2}$ of calibration and SEC about 0.85 and 0.37, respectively.

As for physico-chemical parameters, PLS models were also validated by an independent prediction set of 6 samples. Despite good prediction $\mathrm{R}^{2}$, the predictions are not so good for NF and TE according to REP values over $20 \%$. With regards to FRI, the prediction results are very good, with a $\mathrm{R}^{2}$ of prediction about 0.98 and a REP about $10.2 \%$. So, the soil matter evolution level does not depend on NF or TE separately, but depends on a relation between them, corresponding to the integrating parameter FRI (Table 1). The good correlation and prediction of FRI show that it is a major controlling parameter in our study. The intensity of fires could be a part of the error sources of prediction, as well as the biomass (qualitative and quantitative) presents in the studied sites. Moreover, a recent work [58] showed that the presence of ash could be an interfering factor in the estimation of the maximum temperature reached in burned soils using near-infrared spectroscopy. Another hypothesis could be the interference due to the presence of ash in the estimation of parameters studied in this work, even if it is impossible to estimate it. Nevertheless, this work shows the interest of the fire FRI. PLS regression models are successful in predicting these parameters as the fire recurrence modify NIR spectra of soils. 


\section{Conclusions}

NIR spectroscopy has a number of advantages. It is a rapid, non-destructive and green (because no chemical reagent is needed and no waste is produced) method that doesn't require sample pretreatment. Despite the impossibility to directly interpret a NIR spectrum by correlating the intensity or the surface of peaks with concentrations, NIR spectroscopy coupled with chemometric methods confirms its usefulness for monitoring the forest soils affected by fires.

It clearly appears that the evaluation of the fire recurrence of unknown samples is possible with PCA and particularly the evaluation of the time elapsed since the last fire.

This study shows that NIR spectroscopy coupled with PLS is a valuable tool for soil monitoring, particularly for the prediction of the total organic carbon, total nitrogen, organic carbon and $\mathrm{UVSA}_{254}$ of humic substances, phosphorus, $\mathrm{Mg}^{+}, \mathrm{Ca}^{2+}$ and $\mathrm{NH}_{4}{ }^{+}$. However, further investigation should to be carried out in this field to try to make successful predictions of $\mathrm{K}^{+}$, organic carbon in humic and fulvic acids and HS UVSA 280 .

Furthermore, the proposed recurrence index can be predicted easily. NIR spectroscopy appears to be a very valuable tool to evaluate the fire effects on soils, to study the spatial variability, to map more or less burned areas and to apply adequate rehabilitation techniques, like reforestation or organic enrichment. A larger number of studied samples could lead to more robust models for a better prediction, but this study is a very promising first approach.

\section{Acknowledgements}

Financial support was provided by Region PACA, the IRISE project (http://irise.mediasfrance.org/) funded by the European Union, Forest Focus Regulation (No 2152/2003) and the French Ministry of Agriculture and Fisheries. The authors wish to thank the IRISE staff for considerable work concerning in situ experiment and sampling, in particular Max Bresson for equipment support and active sampling.

\section{References}

[1] M.A. Olivella, T.G. Ribalta, A.R. de Febrer, J.M. Mollet, F.X.C. de las Heras, Sci. Total Environ., 355 (2006) 1.

[2] G. Certini, Oecologia, 143 (2005) 1.

[3] C. Li, Ecol. Model., 154 (2002) 103.

[4] D.F. Merrill, M.E. Alexander, Glossary of Forest Fire Management Terms, in National Research Council of Canada, Canadian Committee on Forest Fire management, Ottawa, Ontario, Publication NRCC No. 26516, 1987.

[5] J.K. Agee, Fire Ecology of Pacific Northwest Forests, in Island Press, Washington, D.C. ,1993.

[6] E. Ben-Dor, A. Banin, Soil Sci. Soc. Am. J., 59 (1995) 364.

[7] C. Chang, D.A. Laird, M.J. Mausbach, C.R. Hurburgh, Soil Sci. Soc. Am. J., 65 (2001) 480.

[8] B.W. Dunn, H.G. Beecher, G.D. Batten, S. Ciavarella, Aust. J. Exp. Agr., 42 (2002) 607.

[9] D.F. Malley, L. Yesmin, R.G. Eilers, Soil Sci. Soc. Am. J., 66 (2002) 1677.

[10] K.D. Shepherd, M.G. Walsh, Soil Sci. Soc. Am. J., 66 (2002) 988.

[11] D. Cozzolino, A. Moron, J. Agr. Sci., 140 (2003) 65.

[12] M. Chodak, P. Khanna, B. Horvarth, F. Beese, J. Near Infrared Spec., 12 (2004) 315.

[13] Y. He, M. Huang, A. Garcia, A. Hernandez, H. Song, Comput. Electron. Agr., 58 (2007) 144.

[14] R. Zornoza, C. Guerrero, J. Mataix-Solera, K.M. Scow, V. Arcenegui, J. Mataix-Beneyto, Soil Biol. Biochem., 40 (2008) 1923.

[15] O. Galtier, N. Dupuy, Y. Le Dréau, D. Ollivier, C. Pinatel, J. Kister, J Artaud, Anal. Chim. Acta, 595 (2007) 136.

[16] C. Guerrero, J. Mataix-Solera, V. Arcenegui, J. Mataix-Beneyto, I. Gómez, Soil Sci. Soc. Am. J., 71 (2007) 1029. 
[17] M. Schnitzer, Organic matter characterization, in B.L. Page, R.H. Miller, D.R. Keeney (Ed.), Methods of Soil Analysis, Part 2, Chemical and Microbiological Properties, second ed., Agronomy Monograph No. 9, Madison, 1982, pp. 581-594.

[18] S. Traina, J. Novak, N. Smeck, J. Environ. Qual., 19 (1990) 151.

[19] R. Chen, J.L. Bada, Mar. Chem., 45 (1994) 31.

[20] P. Viaux, Science du Sol, 1 (1981) 73.

[21] T. Sterckeman, H. Ciesielski, Principaux facteurs influant sur la détermination de l'azote minéral des sols, in Frontières (Ed.), L'azote et le soufre des sols - Troisièmes journées de l'analyse de terre, Blois, Gif sur Yvette, 1991, pp. 101-121.

[22] M. D. Krom, The Analyst, 105 (1980) 305.

[23] P. L. Searle, The Analyst, 109 (1984) 549.

[24] G. Joret, J. Hebert, Ann. Agron., 2 (1955) 233.

[25] L. Duval, Chim. Anal., 45 (1963) 237.

[26] D. Knudsen, G.A. Peterson, P. Pratt, Lithium, Sodium and Potassium, in American Society of Agronomy and Soil Science Society of America Journal. Methods of Soil Analysis, 1982, Madison, Vol. 2, pp. 225-246.

[27] G.W. Thomas, Agronomie, 9 (1982) 154.

[28] H. Ciesielski, T. Sterckeman, Agronomie, 17 (1997) 9.

[29] N. Kettaneh, A. Berglund, S. Wold, Comput. Stat. Data An., 48 (2005) 69.

[30] S. Millar, P. Robert, M.F. Devaux, R.C.E. Guy, P. Maris, Appl. Spectrosc., 50 (1996) 1134.

[31] J.M. Andrès, M.T. Bona, Anal. Chim. Acta, 535 (2005) 123.

[32] M. Fuller, P.R. Griffiths, Anal. Chem., 50 (1988) 1906.

[33] D.M. Haaland, E.V. Thomas, Anal. Chem., 60 (1988) 1193.

[34] Y.L. Liang, O.M. Kvalheim, Chemometr. Intell. Lab., 32 (1996) 1.

[35] A. Savitzky, M.J.E. Golay, Anal. Chem., 36 (1964) 1627.

[36] P.H. Fidencio, R.J. Poppi, J.C. Andrade, H. Cantarella, Commun. Soil Sci. Plan., 33 (2002) 1607.

[37] A. Vergnoux, M. Guiliano, Y. Le Dréau, J. Kister, N. Dupuy, P. Doumenq, Sci. Total Environ., 407 (2009) 2390.

[38] E. Chuvieco, D. Riaño, F.M. Danson, P. Martin, J. Geophys. Res., 111 (2006) 4.

[39] L.W. Dennis, G.E. Maciel, P.G. Hatcher, B.R.T. Simoneit, Geochim. Cosmochim. Acta, 46 (1982) 901.

[40] G. Almendros, J. Dorado, F.J. Gonzalez-Vila, F. Martin, J. Anal. Appl. Pyrol., 40 (1997) 599.

[41] J.A. Baldock, R.J. Smernik, Org. Geochem., 33 (2002) 1093.

[42] F.J. Gonzalez-Vila, P. Tinoco, G. Almendros, F. Martin, J. Agr. Food Chem., 49 (2001) 1128.

[43] H. Knicker, G. Almendros, F.J. Gonzalez-Vila, F. Martin, H.D. Lüdemann, Soil Biol. Biochem., 28 (1996) 1053.

[44] G. Almendros, H. Knicker, F.J. Gonzalez-Vila, Org. Geochem., 34 (2003) 1559.

[45] G.H. Rashid, Plant Soil, 103 (1987) 89.

[46] C. Chandler, P. Cheney, P. Thomas, L. Trabaud, D. Williams, Forest fire behavior and effects, in Wiley (Ed.), Fire in Forestry, vol. I, New York, 1983.

[47] L.F. DeBano, J. Hydrol., 231(2000) 195.

[48] R.A. Shakesby, S.H. Doerr, Earth-Sci. Rev., 74 (2006) 269.

[49] F. Diaz-Fierros, B.E. Rueda, R. Pérez Moreira, Catena, 14 (1987) 189. 
[50] D.H. McNabb, F.J. Swanson, Effects of fire on soil erosion, in J.D. Walstad, S.R. Radosevich, D.V. Sandberg (Ed.), Natural and prescribed fire in Pacific Northwest forests, Corvallis (OR): Oregon State Univ. Press, 1990, pp. 159-76.

[51] V. Andreu, J.L. Rubio, J. Forteza, R. Cerni, Int. J. Wildland Fire, 6 (1996) 53.

[52] W. Saeys, A.M. Mouazen, H. Ramon, Biosyst. Eng., 91, (2005) 393.

[53] I. Kamrunnahar, B. Singh, A. McBratney, Aust. J. Soil Res., 41 (2003) 1101.

[54] G. Fystro, Plant Soil, 246 (2002) 139.

[55] B. Ludwig, P.K. Khanna, J. Bauhus, P. Hopmans, Forest Ecol. Manag., 171 (2002) 121.

[56] K. Islam, B. Stingh, A. McBratney, Aust. J. Soil Res., 41 (2003) 1101.

[57] P.D. Martin, D.F. Malley, G. Manning, L. Fuller, Can. J. Soil Sci., 82 (2002) 413.

[58] V. Arcenegui, , C. Guerrero, J. Mataix Solera, J. Mataix Beneyto, R. Zornoza, J. Morales, A.M. Mayoral, Catena (2008), doi:10.1016/j.catena.2007.11.00 